ORIGINAL ARTICLE

\title{
Maternal Education and Acute Diarrhea Among Children Aged 2-5 Years In Pakistan: Cross Sectional Study
} \author{
ZAINUB $^{6}$, TALHA LAIQUE7 ${ }^{\star}$ \\ ${ }^{1}$ Department of Physiology, Islamic International Dental College Islamabad-Pakistan \\ ${ }^{2}$ Asst. MO I/C Family wing, PEMH.-Pakistan \\ ${ }^{3}$ Department of Biochemistry, Mohi-ud-Din Islamic Medical College Mirpur AJ\&K.-Pakistan \\ ${ }^{4}$ Department of Physiology, CMH Kharian Medical College, Kharian Cantt.-Pakistan \\ ${ }^{5}$ Asst. Comdt. P \& A, PEMH.-Pakistan \\ ${ }^{6}$ Department of Biochemistry, Islamic International Dental College Islamabad-Pakistan \\ ${ }^{7}$ Department of Pharmacology, Allama lqbal Medical College, Lahore-Pakistan \\ Correspondence to: Dr. Talha Laique, Email: talhalaique51@gmail.com, Tel:+92-331-0346682
}

FATIMA EHSAN ${ }^{1}$, AYESHA EHSAN ${ }^{2}$, WAJAHAT ULLAH KHAN ${ }^{3}$, RIZWAN MASUD ${ }^{4}$, HAMAD HANIF ${ }^{5}$, ABEERAH

\begin{abstract}
Childhood diarrheal disease is the second leading cause of death globally. All over the world, children below five years of age experience, on average, 3.2 episodes of diarrhea per year.

Objectives: To explore an association of maternal education with childhood diarrhea in Pakistan.

Study Design: Cross sectional study.

Methodology: This study was conducted from Aug 2016 to Jan 2017 in Combined Military Hospital (CMH), Peshawar following approval from ethical review board. Total children under study were 363 aged 2 to 5 years, amid whom 121 were acute diarrhea cases and 242 were healthy controls leading to cases control ratio as 1:2. Data collection was done through semi structured questionnaire asked from mothers.

Statistical analysis: Data was analyzed by SPSS software, version 22 . To compare the association of maternal education with acute diarrhea, chi square test was applied at $5 \%$ level of significance. Statistical significance was taken at $p$ value $<0.05$

Results: In present study, there was significant association between formal education of mothers and acute diarrhea with a highly statistically significant association $(p<0.001)$ observed showing increased proportion of childhood diarrhea, with increasing levels of education in mothers.

Conclusion: We concluded that a significant increase in childhood diarrhea with higher levels of maternal education refutes the commonly observed finding. We need to further probe the underlying causes to minimize this high observed morbidity.

Key Words: Maternal Education, Child Health and Safety and Acute Childhood Diarrhea
\end{abstract}

\section{INTRODUCTION}

Childhood diarrheal disease is the second leading cause of death globally ${ }^{1}$. All over the world, children below five years of age experience, on average, 3.2 episodes of diarrhea per year. An average 1.87 million children are likely to die from diarrhea associated dehydration, most markedly in Asian, African countries along with Latin America ${ }^{2}$. Infectious/unhygienic weaning food and unclean bottle cleaning practices, poor water facility, improper/lack of hand washing, compromised waste disposal, congested housing conditions, and decreased access to basic health facility are major risk factors of childhood diarrheal disease ${ }^{3,4}$.

Since mothers are the primary caregivers for under 5 children, maternal education is also considered a key factor related to childhood mortality ${ }^{5}$. Diarrhea is not fatal itself, lacking proper care and negligent attitudes of mothers towards its treatment and preventive measures lead to high degree of severe dehydration and related complications ${ }^{6}$.

Many demographic studies worldwide show a strong correlation of maternal education with low infant and child mortality ${ }^{7}$. It is generally believed that an educated mother is better able to nurture her child not only in terms of medical care but also, due to individual behavioral changes, in better child health care. In addition to better health interventions by educated mothers, uneducated mothers exhibit repeated fertility and poor delivery care especially in developing countries which may be another reason for the high prevalence of acute diarrhea among infants and under five children ${ }^{8}$. It has been observed that maternal education even at a basic level and in the underprivileged section of society has marked impact on child health and mortality 9 . However, the precise underlying reasons for this connection are still not very clear. It is not apparent if certain aspects/areas of education contribute more to lower risk of childhood diarrhea and other respiratory diseases.

Furthermore, maternal education may also be representing the socioeconomic status of a family or community and thus may make the correlation between maternal education and improved child health care deceptive $^{9}$.

Hence present study was undertaken to assess the correlation of maternal education with acute diarrhea in under five children in this particular setting. It would facilitate the local health policy makers to combat this fight against childhood diarrhea by better understanding of associated risk factors

Objectives: To explore an association of maternal education with childhood diarrhea in Pakistan

Methodology: This study was conducted from Aug 2016 to Jan 2017 in Combined Military Hospital (CMH), Peshawar following approval from ethical review board. Total children under study were 363 aged 2 to 5 years, amid whom 121 
were acute diarrhea cases and 242 were healthy controls leading to cases control ratio as 1:2. Data collection was done through semi structured questionnaire asked from mothers. Both genders were enrolled. Family Outpatient Department FOPD of $\mathrm{CMH}$ was chosen to select children with diarrhea whereas healthy controls were picked from their Immunization center. Children ranging 2-5 years, with acute diarrhea were confirmed by history taking. Those who were cases but were diagnosed with some primary disease such as intestinal diseases, chronic irregular bowel habits, food mal-absorption, children with severe malnutrition (according to modified Gomez Classification) or seriously ill, dehydrated or those children admitted in Intensive care unit were excluded from study.

Statistical Analysis: Data was analyzed through SPSS version 22. To compare the association of maternal education with acute diarrhea, chi square test was applied at $5 \%$ level of significance. A $p$-value $<0.05$ was considered statistically significant. To compare the association of ages of children and mother with their working status, stratified chi square test was applied after stratification based on the educational status of mothers.

\section{RESULTS}

Gender, working status and age distribution were presented as frequency and percentages in table-1 for enrolled subjects. Out of 3633 subjects, majority $(n=223)$ were males while 244 were in age group upto 30 years. Majority mothers were house wives according to present study.

\begin{tabular}{|l|l|l|l|}
\hline Table-1: Distribution of General Parameters as Frequency \& Percentage $(\mathrm{n}=363)$ & Percentage (\%) \\
\hline Variables & Categories & Frequency & 61.4 \\
\hline \multirow{2}{*}{ Gender } & Male & 223 & 38.6 \\
\cline { 2 - 4 } & Female & 140 & 67.2 \\
\hline \multirow{2}{*}{ Age (years) } & Up to 30 & 244 & 32.8 \\
\cline { 2 - 4 } & Above 30 & 119 & 85.1 \\
\hline \multirow{3}{*}{ Working status } & House wives & 309 & 14.9 \\
\cline { 2 - 4 } & Working mothers & 54 & 100.0 \\
\hline Age (Months) & Total & 363 & \\
\hline
\end{tabular}

The educational status of all 363 mothers was observed, $62(17.7 \%)$ mothers had not received any formal education while 301 (82.94\%) had received formal education. The level of education of all mothers and also mothers of children with and without diarrhea are exhibited in table-2.

\begin{tabular}{|c|c|c|c|}
\hline \multirow[t]{3}{*}{ Levels Of Education } & \multicolumn{2}{|l|}{ Diarrhea } & \multirow[t]{3}{*}{ TOTAL } \\
\hline & PRESENT & ABSENT & \\
\hline & $\mathrm{F}(\%)$ & $\mathrm{F}(\%)$ & \\
\hline \multirow{2}{*}{ Received No Education } & 20 & 42 & 62 \\
\hline & $32.30 \%$ & $67.70 \%$ & $100.00 \%$ \\
\hline \multirow[t]{2}{*}{ Primary } & 57 & 161 & 218 \\
\hline & $26.10 \%$ & $73.90 \%$ & $100.00 \%$ \\
\hline \multirow[t]{2}{*}{ Secondary } & 22 & 31 & 53 \\
\hline & $41.50 \%$ & $58.50 \%$ & $100.00 \%$ \\
\hline \multirow{2}{*}{ Undergrad; Grad; and Post grad } & 22 & 8 & 30 \\
\hline & $73.33 \%$ & $26.67 \%$ & $100.00 \%$ \\
\hline \multirow[t]{2}{*}{ TOTAL } & 121 & 242 & 363 \\
\hline & $33.30 \%$ & $66.70 \%$ & $100.00 \%$ \\
\hline
\end{tabular}

Statistically significant association was observed between formal education of mother and acute diarrhea with a $\mathrm{p}<0.001$ and Odds Ratio of 1.06 , although the $95 \% \mathrm{Cl}$ levels moderated the significance, as shown in table-3.

\begin{tabular}{|c|c|c|c|c|c|c|}
\hline \multirow{2}{*}{$\begin{array}{l}\text { Education Of } \\
\text { Mother }\end{array}$} & \multicolumn{2}{|l|}{ Diarrhea } & \multirow[b]{2}{*}{$\begin{array}{l}\text { Total } \\
\mathrm{F}(\%)\end{array}$} & \multirow[b]{2}{*}{$p$-value } & \multirow[t]{2}{*}{ ODDS RATIO } & \multirow[t]{2}{*}{ 95\% Confidence Interval } \\
\hline & $\begin{array}{l}\text { PRESENT } \\
F(\%)\end{array}$ & $\begin{array}{l}\text { ABSENT } \\
\mathrm{F}(\%)\end{array}$ & & & & \\
\hline $\begin{array}{l}\text { Received No Formal } \\
\text { Education }\end{array}$ & $\begin{array}{l}20 \\
32.3 \%\end{array}$ & $\begin{array}{l}42 \\
67.7 \%\end{array}$ & \begin{tabular}{|l|}
62 \\
$100.0 \%$
\end{tabular} & \multirow{3}{*}{$<0.001^{*}$} & \multirow{3}{*}{1.06} & \multirow{3}{*}{$0.59-1.90$} \\
\hline $\begin{array}{l}\text { Received Formal } \\
\text { Education }\end{array}$ & $\begin{array}{l}101 \\
33.6 \%\end{array}$ & $\begin{array}{l}200 \\
66.4 \%\end{array}$ & $\begin{array}{l}301 \\
100.0 \%\end{array}$ & & & \\
\hline TOTAL & $\begin{array}{l}121 \\
33.3 \%\end{array}$ & \begin{tabular}{l|}
242 \\
$66.7 \%$
\end{tabular} & \begin{tabular}{|l|}
363 \\
$100.0 \%$
\end{tabular} & & & \\
\hline
\end{tabular}

*Statistically significant

Highly statistically significant association was observed between age group of children and occurrence of diarrhea in both educated and uneducated mothers group. As is evident children aged 2-3years are more vulnerable as compared to 4- 
5 years old children, however, the proportion of the children with diarrhea is slightly higher in uneducated mothers as compared to educated mothers $(61.1 \%$ vs $58.8 \%)$ as shown in table- 4 .

\begin{tabular}{|c|c|c|c|c|c|}
\hline \multirow[b]{2}{*}{ Educational Status } & \multirow[b]{2}{*}{ Age Group Of Children } & \multicolumn{2}{|c|}{ Diarrhea } & \multirow[b]{2}{*}{ Total } & \multirow{2}{*}{$p$-value } \\
\hline & & YES & NO & & \\
\hline \multirow{4}{*}{ No Formal Education } & \multirow{2}{*}{ 2-3 Yrs } & 16 & 10 & 26 & \multirow{4}{*}{$0.00^{* *}$} \\
\hline & & $61.5 \%$ & $38.5 \%$ & $100.0 \%$ & \\
\hline & \multirow{2}{*}{ 4-5 YRS } & 4 & 32 & 36 & \\
\hline & & $11.1 \%$ & $88.9 \%$ & $100.0 \%$ & \\
\hline \multirow{4}{*}{ Received Formal Education } & \multirow{2}{*}{ 2-3 Yrs } & 94 & 66 & 160 & \multirow{4}{*}{$0.00^{* *}$} \\
\hline & & $58.8 \%$ & $41.3 \%$ & $100.0 \%$ & \\
\hline & \multirow{2}{*}{ 4-5 YRS } & 7 & 134 & 141 & \\
\hline & & $5.0 \%$ & $95.0 \%$ & $100.0 \%$ & \\
\hline \multirow{2}{*}{ Educational Status Of Mother } & \multirow{2}{*}{ Age Group Of Mothers } & \multicolumn{2}{|c|}{ Diarrhea } & \multirow{2}{*}{ Total } & \multirow[t]{2}{*}{$p$-value } \\
\hline & & Yes & No & & \\
\hline \multirow{2}{*}{ No Formal Education } & Upto 30 Years & \begin{tabular}{|l|}
15 \\
$37.5 \%$ \\
\end{tabular} & \begin{tabular}{|l|}
25 \\
$62.5 \%$ \\
\end{tabular} & \begin{tabular}{|l|}
40 \\
$100.0 \%$ \\
\end{tabular} & \multirow{2}{*}{0.27} \\
\hline & Above 30 Years & \begin{tabular}{|l|}
5 \\
$22.7 \%$ \\
\end{tabular} & \begin{tabular}{|l|}
17 \\
$77.3 \%$ \\
\end{tabular} & \begin{tabular}{|l|}
22 \\
$100.0 \%$ \\
\end{tabular} & \\
\hline \multirow{2}{*}{ Received Formal Education } & Upto 30 Years & \begin{tabular}{|l|}
80 \\
$39.2 \%$ \\
\end{tabular} & \begin{tabular}{|l|}
124 \\
$60.8 \%$ \\
\end{tabular} & \begin{tabular}{|l|}
204 \\
$100.0 \%$ \\
\end{tabular} & \multirow{2}{*}{$0.00^{\star *}$} \\
\hline & Above 30 Years & \begin{tabular}{|l|}
21 \\
$21.6 \%$ \\
\end{tabular} & \begin{tabular}{|l|}
76 \\
$78.4 \%$ \\
\end{tabular} & \begin{tabular}{|l|}
97 \\
$100.0 \%$ \\
\end{tabular} & \\
\hline \multirow[b]{2}{*}{ Educational Status Of Mother } & \multirow{2}{*}{ Working Status } & \multicolumn{2}{|c|}{ Diarrhea } & & \multirow[t]{2}{*}{$p$-value } \\
\hline & & Yes & No & Total & \\
\hline \multirow{2}{*}{ No Formal Education } & House Wife & $\begin{array}{l}20 \\
35.1 \%\end{array}$ & $\begin{array}{l}37 \\
64.9 \%\end{array}$ & $\begin{array}{l}57 \\
100.0 \%\end{array}$ & \multirow{2}{*}{0.10} \\
\hline & Working & $\begin{array}{l}0 \\
.0 \% \\
\end{array}$ & $\begin{array}{l}5 \\
100.0 \% \\
\end{array}$ & $\begin{array}{l}5 \\
100.0 \% \\
\end{array}$ & \\
\hline \multirow{2}{*}{ Received Formal Education } & House Wife & \begin{tabular}{|l|}
70 \\
$27.8 \%$ \\
\end{tabular} & \begin{tabular}{|l|}
182 \\
$72.2 \%$ \\
\end{tabular} & \begin{tabular}{|l|}
252 \\
$100.0 \%$ \\
\end{tabular} & \multirow{2}{*}{$0.00^{* *}$} \\
\hline & Working & \begin{tabular}{|l|}
31 \\
$63.3 \%$
\end{tabular} & \begin{tabular}{l|}
18 \\
$36.7 \%$
\end{tabular} & \begin{tabular}{|l|}
49 \\
$100.0 \%$
\end{tabular} & \\
\hline
\end{tabular}

*Statistically significant

\section{DISCUSSION}

In our study, the risk of diarrheal prevalence was higher in the age group 2-3 years as compared to 4-5years age group of children which was supported by study conducted in Tanzania by Mashoto $\mathrm{KO}^{10}$. They concluded that prevalence of diarrhea decreased gradually after second birthday in under -five as the child grows up. The gender of the child was not a statistically significant predictor of childhood diarrhea which was in line with another study conducted in $\mathrm{Nepal}^{9}$.

Regarding the educational status of mothers in our study, significant association was observed with maternal education and increased incidence of diarrhea. This finding was relatively counter-intuitive when compared to other similar studies where maternal education was positively correlated with decreased diarrheal incidence 7,11 . Maternal education was highlighted especially in developing and underprivileged countries where health policy makers were encouraged to target illiterate and less educated mothers to ensure children's health and safety ${ }^{12}$. There was general consensus on higher diarrheal cases among illiterate mothers ${ }^{13}$.
Household wealth may also overshadow the relationship between maternal education and childhood diarrhea ${ }^{14}$. However, when various levels of education were analyzed in our study it showed an increasing trend of diarrhea among mothers with higher level of education such as graduate and post graduate mothers. The higher education qualification in Pakistan has undergone frequent changes with graduation being completed on an average at 21 to 23 years of age. Up to date no such study can be found showing higher incidence of childhood diarrhea with increasing levels of education. The current education system posed a great stress on our youth which may result in negligence regarding marital family responsibilities in one way or the other ${ }^{15}$. Our results also showed a significant association of young mothers with higher odds of childhood diarrhea as compared to mothers above 30 years of age only in educated mothers group. A cross sectional population-based study in Pernambuco also confirmed our study regarding younger maternal age and childhood diarrhea ${ }^{16}$. This further strengthened our findings that young mothers besides being inexperienced were overburdened with their 
studies. These data proposed that we cannot rely merely on maternal education alone, in terms of expected beneficial effects on child health. Super additive measures may be necessary preconditions for higher levels of maternal education to result in improved child health.

Likewise, when maternal occupation was compared with childhood diarrhea, it was found to have significant positive correlation. Children of working mothers had a higher risk of diarrhea compared with children whose mothers were house wives. A study extracted from the National DHS data using data extraction tools in North West Ethopia also showed that children of mothers who were engaged in any outdoor work were about two times more likely to have diarrhea compared to children of mothers who were not working ${ }^{7}$. Children of working mothers had more chances to have diarrhea than nonworking mothers according to a study conducted by Anteneh $Z A$ further strengthening our findings ${ }^{17}$. This finding contradicted those who suggested that a mother's work was in no conflict to her child's well-being. Mothers' absence from the household not only disturbed the internal system of the home, but with poor socioeconomic support led to undesirable effects on child health 4 .

Limitations: Our study had limitations like financial constraints, lack of resources and lacked genetic workup along-with strategy formation in everyday life.

\section{CONCLUSION}

We concluded that child and mother's age alongwith working status of mother were found to be determinants of acute diarrhea. Gender however didn't show any statistical significance in relation to the diarrhea morbidity. Mother's education, which was the main independent variable in our study exhibited significant association. In parallel, higher levels of maternal education showed increased tendency towards diarrhea in under five-year-old children. This finding raised concerns and needs to be further probed with associated factors as it was counter intuitive to majority of the studies demonstrating a strong association with higher education and decreased childhood diarrhea. Further studies at a wider level should be conducted to further investigate it.

\section{Authors' Contribution:}

FE \& AE: Conception and design of work

WUK \& RM: Collecting and analyzing the data

$\mathrm{HH}, \mathrm{AZ}$ \& $\mathrm{TL}$ : Drafting and revising the manuscript for intellectual content

Acknowledgement: All authors are thankful to Allah SubhanaoTaála who made it possible.

Conflict of Interest: None to declare

Financial Disclosure: None

\section{REFERENCES}

1. Pinzón-Rondón ÁM, Zárate-Ardila C, Hoyos-Martínez A, Ruiz-Sternberg ÁM, Vélez-van-Meerbeke A. Country characteristics and acute diarrhea in children from developing nations: a multilevel study. BMC Public Health. 2015 Dec 1;15(1):811.

2. Seyal T, Hanif A. Knowledge, Attitude and Practices of the Mothers and Doctors Regarding Feeding. Annals of King Edward Medical University. 2009;15(1):38-

3. Luby SP, Agboatwalla M, Hoekstra RM. The variability of childhood diarrhea in Karachi, Pakistan, 2002-2006. The American journal of tropical medicine and hygiene. 2011 Jun 1;84(6):870-7.

4. George CM, Perin J, De Calani KJ, Norman WR, Perry H, Davis Jr TP, Lindquist ED. Risk factors for diarrhea in children under five years of age residing in peri-urban communities in Cochabamba, Bolivia. The American journal of tropical medicine and hygiene. 2014 Dec 3;91(6):1190-6.

5. Desmennu AT, Oluwasanu MM, John-Akinola YO, Oladunni $O$, Adebowale SA. Maternal education and diarrhea among children aged 0-24 months in Nigeria. African journal of reproductive health. 2017;21(3):27-36.

6. Anigilaje EA. Management of diarrhoeal dehydration in childhood: A review for clinicians in developing countries. Frontiers in pediatrics. 2018 Feb 23;6:28.

7. Mihrete TS, Alemie GA, Teferra AS. Determinants of childhood diarrhea among underfive children in Benishangul Gumuz regional state, north West Ethiopia. BMC pediatrics. 2014 Dec 1;14(1):102.

8. Ekpo O. Careseeking for childhood diarrhoea at the primary level of care in communities in Cross River State, Nigeria. Journal of epidemiology and global health. 2016 Dec 1;6(4):303-13.

9. Kalakheti B, Panthee K, Jain KC. Risk factors of diarrhea in children under five years in urban slums. Journal of Lumbini medical college. 2016 Dec 30;4(2):94-8.

10. Mashoto KO, Malebo HM, Msisiri E, Peter E. Prevalence, one week incidence and knowledge on causes of diarrhea: household survey of under-fives and adults in Mkuranga district, Tanzania. BMC public health. 2014 Dec 1;14(1):985.

11. Rehman Inayat Shukr SA, Khanum T, Mehmood T. Is there a link between maternal illiteracy and childhood diarrhea?. Rawal Medical Journal. 2009 Jul;34(2):199-202.

12. Bado AR, Susuman AS, Nebie El. Trends and risk factors for childhood diarrhea in sub-Saharan countries (1990-2013): assessing the neighborhood inequalities. Global health action. 2016 Dec 1;9(1):30166.

13. Alebel A, Tesema C, Temesgen B, Gebrie A, Petrucka P, Kibret GD. Prevalence and determinants of diarrhea among under-five children in Ethiopia: A systematic review and meta-analysis.

14. Osumanu IK. Household environmental and behavioural determinants of childhood diarrhoea morbidity in the Tamale Metropolitan Area (TMA), Ghana. Geografisk TidsskriftDanish journal of geography. 2007 Jan 1;107(1):59-68.

15. Paty M. Oxford Islamic Studies Online. The Charleston Advisor. 2012 Apr 1;13(4):23-5.Vasconcelos MJ, Rissin A, Figueiroa JN, Lira PI, Batista Filho M. Factors associated with diarrhea in children under five years old in the state of Pernambuco, according to surveys conducted in 1997 and 2006. Revista de saude publica. 2018 May 3;52:48.

17. Anteneh ZA, Andargie K, Tarekegn M. Prevalence and determinants of acute diarrhea among children younger than five years old in Jabithennan District, Northwest Ethiopia, 2014. BMC public health. 2017 Dec;17(1):99. 